\title{
Study on the Penetration of Al into Fe-3 \%Si Thin Sheet Using PVD Method and Its Application in Preparing Fe-6.5\%(Si+Al) Alloy
}

\author{
Guang-Ke TIAN ${ }^{*}$, Jie REN and Tian-Guo MA \\ National Engineering Research Center for Technology and Equipment of Green Coating, \\ Lanzhou Jiaotong University, \\ Lanzhou, China \\ email: tiangke@mail.Izjtu.cn.
}

Keywords: Fe-6.5 \%(Si+Al) alloy; Magnetron-sputtering; Diffusion annealing; Penetration mechanism of Al.

\begin{abstract}
Fe-6.5 \% Si alloy has excellent soft magnetic properties but is hardly able to being produced by conventional hot-cold rolling processes. It is well known that a small amount of Al adding into Fe-Si alloys is benefit to enhancing the alloy's soft magnetic properties and its working performance. In the present work pure Al layers were deposited onto $\mathrm{Fe}-3 \% \mathrm{Si}$ thin sheets using direct current (DC) magnetron sputtering and followed by diffusion annealing to promote $\mathrm{Al}$ penetrating into low-Si steel substrates. Based on the experimental and simulation results, the mechanism of Al penetrated into low-Si steel substrate was subjected to rate-controlling and $\mathrm{Si}$ uphill diffusion only occurred under the influence of penetrated Al being gradient distributed. As deposited Al layer's thickness reached to $32 \mu \mathrm{m}$ onto $0.23 \mathrm{~mm} \mathrm{Fe}-3 \% \mathrm{Si}$ substrate and followed by a diffusion annealing at $1200{ }^{\circ} \mathrm{C}$ for $6 \mathrm{~h}$, Fe-6.5\%( $\left.\mathrm{Si}+\mathrm{Al}\right)$ alloy can be achieved. Electron dispersive spectroscopy (EDS) analyses showed that both Si and penetrated Al profiles were evenly distributed along the depth of the prepared $\mathrm{Fe}-6.5 \%(\mathrm{Si}+\mathrm{Al})$ alloy, and the microstructure was also uniform and density. The resistivity of $\mathrm{Fe}-6.5 \%(\mathrm{Si}+\mathrm{Al})$ alloy was close to that of $\mathrm{Fe}-6.5 \% \mathrm{Si}$ alloy, but the working performance of the former was observed evidently better than the latter.
\end{abstract}

\section{Introduction}

Fe-6.5\% (weight percentage, hereinafter) Si alloy has excellent soft magnetic properties such as higher permeability, higher saturation magnetization, near to zero magnetostriction and lower core loss than conventional $\mathrm{Fe}-3 \% \mathrm{Si}$ steel sheets. However, due to the appearance of ordering brittle phases such as B2 or DO3, the high-Si alloys are hardly able to being produced by conventional hot-cold rolling processes [1-5]. Several techniques were developed to overcome the drawbacks, in an attempt to produce Fe-6.5\% $\mathrm{Si}$ thin sheets [6-9], but only chemical vapor deposition (CVD) realized low-scale commercial production, which is still far away from meeting the great demands required by electromagnetic applications [4]. Many researchers found that silicon steel sheets with a small amount of Al could optimize its magnetic properties and working performance. A. H. Kasama et al prepared $\mathrm{Fe}-3 \% \mathrm{Si}-3.5 \% \mathrm{Al}$ alloy by spray-formed approach, and found its magnetic properties were very well when compared with binary Fe-6.5\% $\%$ Si. Claudemiro Bolfarini studied the magnetic properties of spray-formed Fe-6.5\% Fe-6.5\%Si alloy could suppress the generation of B2 structure and improve the Fe-Si alloy ductility [10]. J. Barros, et al assessed the feasibility of increasing the concentration of ( $\mathrm{Si}, \mathrm{Al}$ ) in low-Si steel sheet by hot dipping and diffusion treatment [11]. All the above researches concluded that Al alloying into Fe-Si binary systems being advantage to its properties, but whether Fe-Si-Al alloys, especially $\mathrm{Fe}-6.5 \%(\mathrm{Si}+\mathrm{Al})$ alloy could be prepared by penetrated $\mathrm{Al}$ into $\mathrm{Fe}-3 \% \mathrm{Si}$ thin sheet was less reported, and what's the interaction effect between penetrated $\mathrm{Al}$ and solved $\mathrm{Si}$ in Fe matrix was still not very clear. This work started from depositing pure Al layers onto Fe-3\%Si steel substrates by PVD method and followed by a diffusion annealing at high temperature in vacuum, to evaluate the feasibility of preparing $\mathrm{Fe}-6.5 \%(\mathrm{Si}+\mathrm{Al})$ alloy, and clarify the penetration mechanism of Al into low-Si steel substrate. 


\section{Experimental}

$0.23 \mathrm{~mm}$ thick commercial $\mathrm{Fe}-3 \% \mathrm{Si}$ steel sheet was degreased and cut into $10 \mathrm{~mm} \times 20 \mathrm{~mm}$ for starting substrates. Al layers (Al target with purity of $99.99 \%$ ) were deposited on the starting substrates by using direct current (DC) magnetron sputtering. Table 1 presents the deposition parameters. The as-deposited samples were annealed with a heating rate of $10{ }^{\circ} \mathrm{C} / \mathrm{min}$ in a vacuum of $8 \times 10^{-4} \mathrm{~Pa}$ at temperatures ranging from 950 to $1200{ }^{\circ} \mathrm{C}$ and holding for $0.5-6$ hours. Structure of the samples were characterized by X-ray diffractometer (XRD) XPERT-PRO with $\mathrm{Cu}$ Ka radiation $(\lambda=0.1540598 \mathrm{~nm})$. Composition and microstructure along the sample cross-section were analyzed by Quanta 450 FEG scanning electron microscopy (SEM) equipped with electron dispersive spectroscopy (EDS). The micro-hardness was measured by HVD-1000IS digital micro-hardness tester along the polished cross-section with a load of $100 \mathrm{~g}$ and the imprinting time of 10 seconds. The electrical resistivity was measured using a four-probe technique.

TABLE 1. Detail parameters of deposition processes.

\begin{tabular}{ccccc}
\hline $\begin{array}{c}\text { Ar } \\
\text { pressure }\end{array}$ & $\begin{array}{c}\text { Power } \\
\text { density }\end{array}$ & $\begin{array}{c}\text { Target-substrate } \\
\text { distance }\end{array}$ & $\begin{array}{c}\text { Substrate } \\
\text { temperature }\end{array}$ & $\begin{array}{c}\text { Deposition } \\
\text { rate }\end{array}$ \\
\hline $0.8 \mathrm{~Pa}$ & $\begin{array}{c}6.3 \\
\mathrm{~W} / \mathrm{cm}^{2}\end{array}$ & $80 \mathrm{~mm}$ & $200^{\circ} \mathrm{C}$ & $137 \mathrm{~nm} / \mathrm{min}$ \\
\hline
\end{tabular}

\section{Results and Discussion}

The effect of annealing temperature and time on the penetration of Al into low-Si steel substrates was investigated firstly. Fig.1a exhibits $\mathrm{Al}$ concentration profiles of the samples started with depositing $8 \mu \mathrm{m}$ thickness Al layers and annealed at $950{ }^{\circ} \mathrm{C}, 1000^{\circ} \mathrm{C}, 1100^{\circ} \mathrm{C}$ and $1200{ }^{\circ} \mathrm{C}$ for $2 \mathrm{~h}$, respectively, where all the symbols represent experimental results and same color curves represent their Gauss-fitting. With the elevation of annealing temperature, the concentration gradients of $\mathrm{Al}$ declined, but the penetration depths increased gradually, annealing at $1200{ }^{\circ} \mathrm{C}$ for $2 \mathrm{~h}$ led to $\mathrm{Al}$ penetrating throughout the substrate thickness and almost being homogeneous distribution. Considering of possible evaporation of $\mathrm{Al}$ at higher temperatures in vacuum [12], the annealing temperature didn't exceed more than $1200{ }^{\circ} \mathrm{C}$ in the experimental.

The inset table in Fig. 1a lists the corresponding integrated areas between Al concentration profile curves and abscissa axis, which can be used to assess the dependence of annealing temperature on the total $\mathrm{Al}$ amount penetrated into the starting substrate. As temperature is increased from $950{ }^{\circ} \mathrm{C}$ to $1100{ }^{\circ} \mathrm{C}$, the integrated areas increase from 147 (here ignoring its unit) to 188 , meaning that more amount of $\mathrm{Al}$ penetrated into the substrate from deposited $\mathrm{Al}$ layers at higher temperatures. As annealing temperature is up to $1100{ }^{\circ} \mathrm{C}$ and $1200{ }^{\circ} \mathrm{C}$, the integrated areas reach to nearly a constant of 188 , implies that annealing above $1100{ }^{\circ} \mathrm{C}$ promises all or the most of the deposited Al penetrated into the substrates. For the reason of the deposited Al layer being finite as diffusion source, the concentration-depth profiles can be described by the thin-film solution of Fick's Second Law [13]:

$$
C(x, t)=\frac{S}{2 \sqrt{\pi D t}}\left[e^{-\frac{x^{2}}{4 D t}}+e^{-\frac{(x-2 d)^{2}}{4 D t}}+\cdots\right]
$$

Where $S, x, d, D$ and $t$ represent the $\mathrm{Al}$ amount as diffusant source, the distance of Al penetration, the thickness of the substrate, diffusion coefficient and annealing time, respectively. Based on trial method, when we try to set $S$ value as $410, t$ equals to $7200 \mathrm{~s}$, and $D$ values being $4.2 \times 10^{-13} \mathrm{~m}^{2} / \mathrm{s}$ at $1100{ }^{\circ} \mathrm{C}$ and $1.5 \times 10^{-12} \mathrm{~m}^{2} / \mathrm{s}$ at $1200{ }^{\circ} \mathrm{C}$, Al concentrations after diffusion annealing at $1100{ }^{\circ} \mathrm{C}$ and 
$1200{ }^{\circ} \mathrm{C}$ for $2 \mathrm{~h}$ can be calculated according to formula (1) and displayed in Fig. $1 \mathrm{~b}$. It can be seen that the calculated values were in good agreement with the experimental results. Thus, from Arrhenius equation:

$$
D=D_{0} \exp \left(-\frac{Q}{R T}\right)
$$

We can furthermore achieve the activation energy $Q$ of Al penetrated into low-Si steel sheet being about $214 \mathrm{~kJ} / \mathrm{mol}$. The value also is in well agreement with previous reports [14]. Based on the experimental and simulation results, the mechanism of $\mathrm{Al}$ penetrated into $\mathrm{Fe}-3 \% \mathrm{Si}$ substrate can be concluded being subjected to rate-controlling.

Fig. 2 demonstrates annealing time dependence of $\mathrm{Al}$ concentration profiles for samples coated with $8 \mu \mathrm{m} \mathrm{Al}$ layer and annealed at $1200{ }^{\circ} \mathrm{C}$. The penetration depth of Al increased with the annealing time. Meanwhile, the gradient of $\mathrm{Al}$ content decreased with annealing time, showing a homogeneous diffusion characterization.

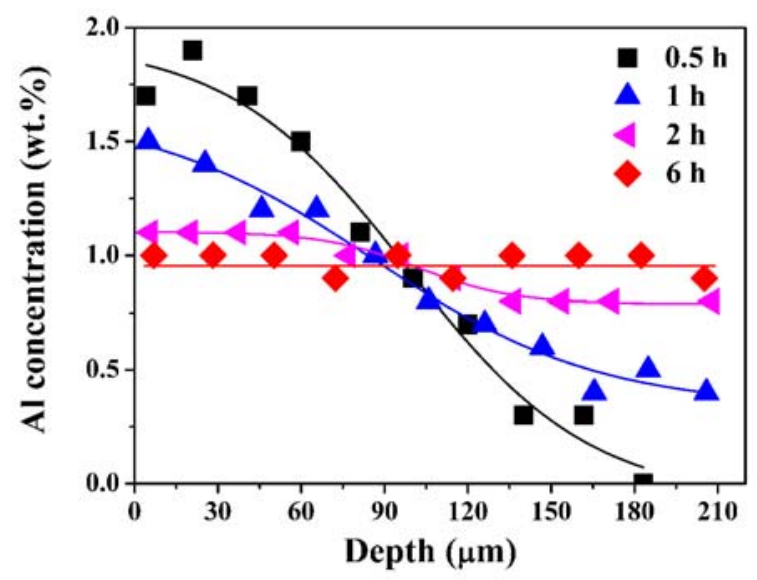

Figure 2. Cross-sectional Al concentration profiles for samples deposited with $8 \mu \mathrm{m}$ Al layers and annealed at $1200{ }^{\circ} \mathrm{C}$ for various time.

To clarify the interaction effect of $\mathrm{Al}$ and $\mathrm{Si}$ during diffusion annealing, both $\mathrm{Si}$ and $\mathrm{Al}$ distribution profiles along the cross-section for the samples processed by coated with $8 \mu \mathrm{m}$ thickness Al layer and subsequent annealing at $1200{ }^{\circ} \mathrm{C}$ for $10 \mathrm{~min}, 2 \mathrm{~h}$ and $6 \mathrm{~h}$ were displayed in Fig. 3, at where the black dotting line refers to the starting content of $\mathrm{Si}$ in the substrate. It can be found in Fig. 3a that after only 10 minutes annealing at $1200{ }^{\circ} \mathrm{C}$, Al penetrated into the substrate nearly $80 \mu \mathrm{m}$ depth and having a steep decline distribution. Meanwhile, Si distribution in the substrate exhibits a very different profile, which can be divided along the depth into three regions. Region "I", Si content increases with the depth but lower than the starting value of 3\%. Region "II", there is a maximum peak of Si content about 3.8\% in the depth near the diffusion front edge of Al. Region "III", Si content keeps a constant value of about $3.3 \%$ where no Al atoms can be detected.

In fact, the diffusion couple in the present work consisted of $\mathrm{Fe}-3 \% \mathrm{Si}$ alloy and pure $\mathrm{Al}$ layer. When the as-deposited samples were heated up over than $\mathrm{Al}$ melt point of $660^{\circ} \mathrm{C}$, the pure $\mathrm{Al}$ layers would be molten as liquid layer coated on the Fe-Si substrates. Thus the system can be classified as solid/liquid diffusion couple. At the start of annealing, a solid/liquid interface formed at the plane of initial contact and a number of binary and ternary phases formed due to the diffusion flux of Fe and $\mathrm{Si}$ in $\mathrm{Al}$ liquid and an opposite flux of $\mathrm{Al}$ in solid $\mathrm{Fe}-3 \% \mathrm{Si}$ substrate. Therefore, Si content in region "I" in Fig. 3a being lower than the starting value of $3 \%$ can be explained as $\mathrm{Fe}$ and $\mathrm{Si}$ atoms diffused into Al liquid layer and simultaneously penetrated Al having a dilution effect on the content of $\mathrm{Si}$. In region "II", Si content improved and deviated greatly from the starting value should be attributed to the uphill diffusion of Si under the repulsive effect of penetrated Al which changed the chemical potential in Fe-Si-Al ternary system, similar phenomenon also occurred in 
literatures [14] and [15]. In region "III" no Al atoms can be detected but Si content kept greater than the starting value of $3 \%$, we guess it results from the diffusivity of Fe in liquid Al being greatly quicker than that of $\mathrm{Al}$ in solid Fe-Si substrate $[16,17]$, a net flux of Fe diffusing from the bulk substrate to liquid layer and leading correspondingly to a Si-rich than the starting value region "III" formation.

Until after $6 \mathrm{~h}$ annealing at $1200^{\circ} \mathrm{C}$ as shown in Fig. 3b, with the penetrated Al became uniform distribution along the depth of the substrates, the distribution profiles of Si resumed evenly. However, the average content of Si was still bigger than the starting value. The interaction between $\mathrm{Al}$ and Si may demonstrate that Si uphill diffusion in Fe-Si-Al ternary system only occurred under the influence of Al being gradient distributed.

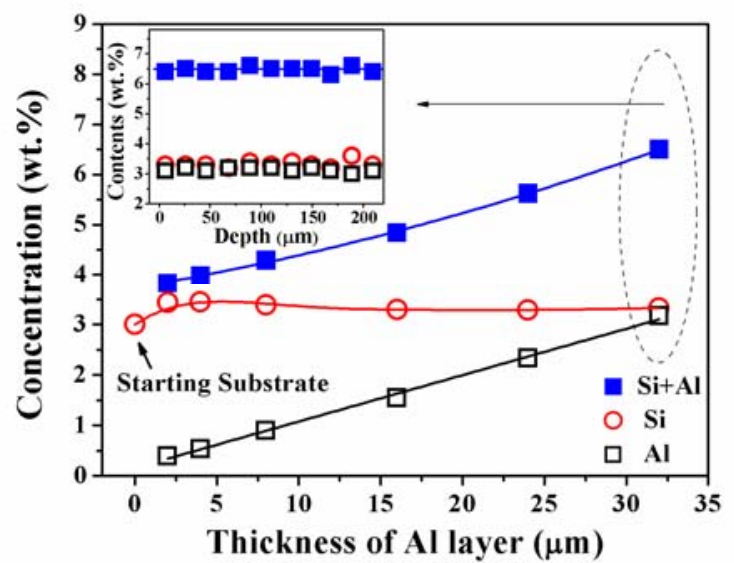

Figure 4. Dependence of the average contents of $\mathrm{Al}$ and $\mathrm{Si}$ and meanwhile their sum on the deposited $\mathrm{Al}$ amount. The inset shows both $\mathrm{Si}$ and $\mathrm{Al}$ were homogenously distributed in the prepared $\mathrm{Fe}-6.5 \%(\mathrm{Si}+\mathrm{Al})$ alloy

To investigate the dependence of $\mathrm{Al}$ and $\mathrm{Si}$ concentrations on the deposited $\mathrm{Al}$ amount, the starting substrate deposited with various thickness of Al layers and all followed by annealing at $1200{ }^{\circ} \mathrm{C}$ for $6 \mathrm{~h}$. EDS measurement results shown that after $6 \mathrm{~h}$ annealing at $1200{ }^{\circ} \mathrm{C}$, all the penetrated $\mathrm{Al}$ and $\mathrm{Si}$ in the substrates were homogenously distributed across the sections. Thus the average contents of $\mathrm{Si}$ and $\mathrm{Al}$ in the processed alloys were demonstrated in Fig. 4 with the abscissa axis exhibiting corresponding thickness of deposited Al layers. It can be found that the penetrated $\mathrm{Al}$ concentration increased linearly with the deposited Al layer thickness. The average contents of $\mathrm{Si}$ elevated up to a maximum value of $3.45 \%$ when $\mathrm{Al}$ content was near $0.5 \%$, and then declined slowly. As deposited Al layer's thickness reached to $32 \mu \mathrm{m}$ (cross-sectional image showed in Fig. 5a) and after diffusion annealing (cross-sectional image showed in Fig. 5b), the average content of Al increased to $3.17 \%$ and $\mathrm{Si}$ average content was $3.33 \%$, meaning that $\mathrm{Fe}-6.5 \%(\mathrm{Si}+\mathrm{Al})$ alloy was achieved. The inset in Fig. 4 exhibits that both Si and penetrated Al profiles were evenly distributed along the depth of the prepared $\mathrm{Fe}-6.5 \%(\mathrm{Si}+\mathrm{Al})$ alloy, meanwhile Fig. $5 \mathrm{~b}$ demonstrates that its microstructure was also uniform and density after cleaning the residual layer attached in the surface.

The change of Si average contents in Fig. 4 also can be verified from the microstructures of the processed alloys. Fig. 6 shows the XRD patterns of the starting substrate of Fe-3\%Si sheet (sample "A"), the processed alloys with penetrated Al reaching to $0.9 \%$ (sample "B", Si content being at $3.39 \%$ ) and $3.17 \%$ (sample "C", Si content being at $3.33 \%$ ), respectively. The inset in Fig.6 displays the magnified diffraction profiles in the range of $43.5^{\circ}-47^{\circ}$ and corresponding lattice constants calculated according to the $2 \theta$ positions at (110) peaks which were indexed as $\alpha-\mathrm{Fe}(\mathrm{Si})$ or $\alpha-\mathrm{Fe}(\mathrm{Si}, \mathrm{Al})$ solution. It can be seen that the two processed alloys were vastly different with the starting substrate in the positions of (110) peaks and their lattice constants. The (110) peak of sample "C" with greater amount of penetrated $\mathrm{Al}$ shifted toward lower angle side, and its lattice constant of $0.2884 \mathrm{~nm}$ was bigger than that of the starting substrate of $0.2874 \mathrm{~nm}$. But the ones of sample "B" penetrated with $0.9 \% \mathrm{Al}$ varied to opposite direction, higher angle side and its lattice constant being smaller. This could be interpreted from the difference of atomic sizes: the atomic 
radius of $\mathrm{Al}$ is the biggest and that of $\mathrm{Si}$ is the smallest among the ternary system of Fe-Si-Al (Fe: $0.124 \mathrm{~nm}$, Si: $0.118 \mathrm{~nm}$, and Al: $0.142 \mathrm{~nm}$ ) [18], therefore in sample " $\mathrm{C}$ " with the penetration of $\mathrm{Al}$ atoms into Fe-Si matrix substituting $\mathrm{Fe}$ atoms and/or Si atoms, the lattice should be expanded with the increment of $\mathrm{Al}$ content. In contrast, smaller amount of $\mathrm{Al}$ penetrated into the starting substrate such as sample "B", Al content was only $0.9 \%$, as discussed above, the increment of Si from $3 \%$ to $3.39 \%$ may compensate the influence of $\mathrm{Al}$ and play a dominant role in its microstructure, thus the lattice constant was smaller than that of the starting substrate.

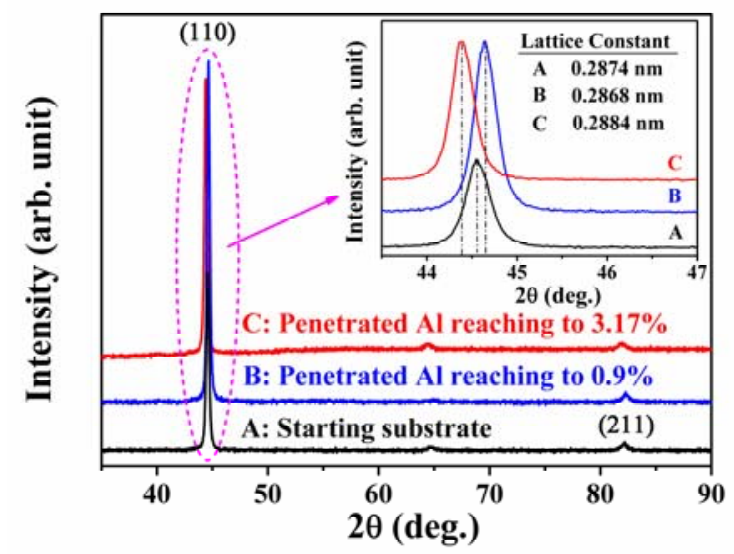

Figure 6. XRD patterns for (A) starting substrate, (B) and (C) with penetrated Al concentration reaching to $0.9 \%$ and $3.17 \%$, respectively. The inset magnifies their diffraction profiles in the range of $43.5-47^{\circ}$ and lists the corresponding lattice constants.

Fig. 7 demonstrates the electrical resistivity and the micro-hardness of the processed alloys with various sum contents of ( $\mathrm{Si}+\mathrm{Al})$. It can be seen that with the increasing of the sum content of $\mathrm{Si}$ and $\mathrm{Al}$ in the processed alloys, both its resistivity and micro-hardness elevated almost linearly. The resistivity and micro-hardness of $\mathrm{Fe}-6.5 \% \mathrm{Si}$ also were displayed in the figure [2]. It can be found that the resistivity of $\mathrm{Fe}-6.5 \%(\mathrm{Si}+\mathrm{Al})$ alloy is very close to that of $\mathrm{Fe}-6.5 \% \mathrm{Si}$ alloy. Higher resistivity of soft magnetic material can be expected being beneficial to reducing its eddy loss, especially at high frequency. As comparing the hardness of $\mathrm{Fe}-6.5 \%(\mathrm{Si}+\mathrm{Al})$ alloy with $\mathrm{Fe}-6.5 \% \mathrm{Si}$ alloy, it can be seen the micro-hardness of $\mathrm{Fe}-6.5 \%(\mathrm{Si}+\mathrm{Al})$ alloy is obviously less than that of Fe-6.5 \% Si alloy, which can be beneficial to its working performance. This has been proved by the photo inserted in Fig. 5b up-right corner that the prepared $\mathrm{Fe}-6.5 \%(\mathrm{Si}+\mathrm{Al})$ alloy can be cut by scissors at ambient temperature and bended to a right angle, which is hardly possible to $\mathrm{Fe}-6.5 \% \mathrm{Si}$ alloy. Better working performance of the $\mathrm{Fe}-6.5 \%(\mathrm{Si}+\mathrm{Al})$ alloy may be attributed to the presence of $\mathrm{Al}$ improving the alloy's ductility by producing changes in stacking fault energy and influencing its micro-structural behavior in the order/disorder transformation [19].

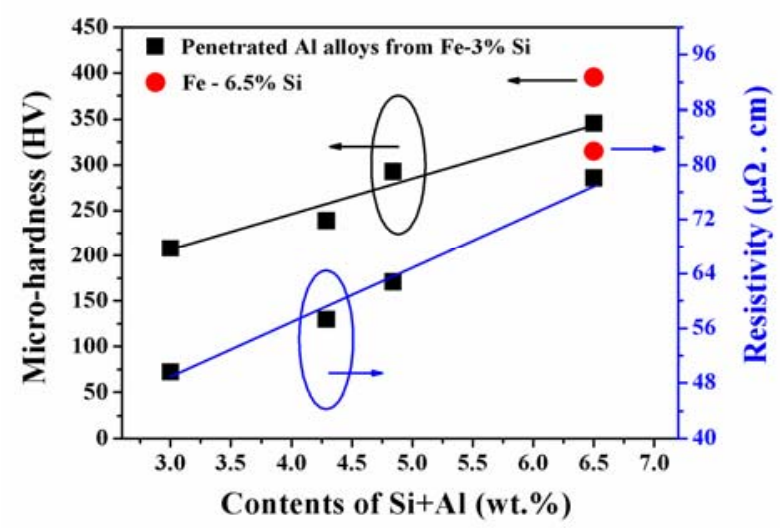

Figure 7. Dependence of the micro-hardness and resistivity for the processed alloys on the sum contents of Si and Al. 


\section{Conclusions}

Pure Al layers were deposited onto low-Si steel substrates using DC magnetron sputtering method and subsequent diffusion annealing was conducted led to penetration of $\mathrm{Al}$ into the substrate. The penetration mechanism of $\mathrm{Al}$ into low-Si steel sheets is subjected to rate-controlling, and its activation energy can be evaluated about $214 \mathrm{~kJ} / \mathrm{mol}$, in good agreement with literatures. Si uphill diffusion in the processed $\mathrm{Fe}-\mathrm{Si}$-Al system only occurred under the influence of $\mathrm{Al}$ being gradient distributed. The resistivity of the prepared $\mathrm{Fe}-6.5 \%(\mathrm{Si}+\mathrm{Al})$ alloy was close to that of $\mathrm{Fe}-6.5 \% \mathrm{Si}$ alloy and its working performance was observed evidently better than the latter.

\section{Acknowledgment}

This work was financially supported by the National Natural Science Foundation of China (Grant No. 51461028) and LZJTU(201602)EP support.

\section{References}

[1] R.M. Bozorth, Ferromagnetism, pp. 75-80, Van Nostrand, New York, 1951.

[2] Y. Takada, M. Abe, S. Masuda, and J. Inagaki, J. Appl. Phys. 64 (1988) 5367.

[3] H. Ninomiya, Y. Tanaka, A. Hiura, and Y. Takada, J. Appl. Phys. 69 (1991) 5358.

[4] H. Haiji, K. Okada, T. Hiratani, M. Abe and M. Ninomiya, J. Magn. Magn. Mater.160 (1996) 109.

[5] Claudio Cassio Lima, Mário Cézar Alves Silva, Maria Dorotéia Costa Sobral, Rodrigo Estevam Coeiho, Claudemiro Bolfarini, J. Alloy. Compd. 586 (2014) S314-S316.

[6] T. Ros-Yáñez, D. Ruiz, J. Barros, Y. Houbaert, J. Alloy. Compd. 369 (2004) 125-130.

[7] R. K. Roy, A. K. Panda, M. Ghosh, A. Mitra and R. N. Ghosh, J. Magn. Magn. Mater.321 (2009) 2865-2870.

[8] Chang-Sheng Li, Cheng-Lin Yang, Guo-Jun Cai, Qi-Wen Wang, Mater. Sci. Eng. A 650 (2016) 84-92.

[9] H. Kasama, C. Bolfarini, C. S. Kiminami and W. J. Botta Filho, Mater. Sci. Eng. A 449-451 (2007) 375-377.

[10]Claudemiro Bolfarini, Mário Cézar Alves Silva, Alberto Moreira Jorge Jr, Claudio Shyinti Kiminami, Walter José Botta. J. Magn. Magn. Mater. 320 (2008) e653-e656.

[11]J. Barros, J. Schneider, Y. Houbaert, J. Magn. Magn. Mater. 320 (2008) e389.

[12]Jose Barros, Benny Malengier, Roger Van Keer and Yvan Houbaert, J. Pha. Equili. Diff., 2005, 26: 417-422.

[13]Helmut Mehrer, Diffusion in Solid, 2007, Springer-Verlag, Berlin Heidelberg: 37-53.

[14]Zhongping He, Yanlin He, Yi Gao, Lin Li, Shuigen Huang, Omer Van der Biest, J. Mater. Sci. Technol., 2011, 27(8): 729-734.

[15]Infante Danzo, B. Malengier, S. Miyar, E. Gomez, K. Verbeken, Y. Houbaert, R. Van Keer and I. De Graeve, Defect Diffu. Forum, 326-328(2012): 428-433.

[16]Yong Du, Y.A. Chang, Baiyun Huang, Weiping Gong, Zhanpeng Jin, Honghui Xu, Zhaohui Yuan, Yong Liu, Yuehui He, F.-Y. Xie, Mater. Sci. Eng. A 363 (2003) 140-151.

[17]Jose Barros, Tanya Ros-Yañez and Yvan Houbaert, Defect diffuse. Forum, 237-240(2005): 1115-1120. 
[18]K. M. Ralls, T. H. Courtney and J. Wulff. Introduction to Materials Science and Engineering, John Wiley and fuhao Sons, New York/London/Syney/Toronto, 1976.

[19]D. R. Lesuer, C. K. Syn, J. D. Whittenberger, M. Carsi, O. A. Ruano, O. D. Sherby, Mater. Sci. Eng. A 317 (2001)101.
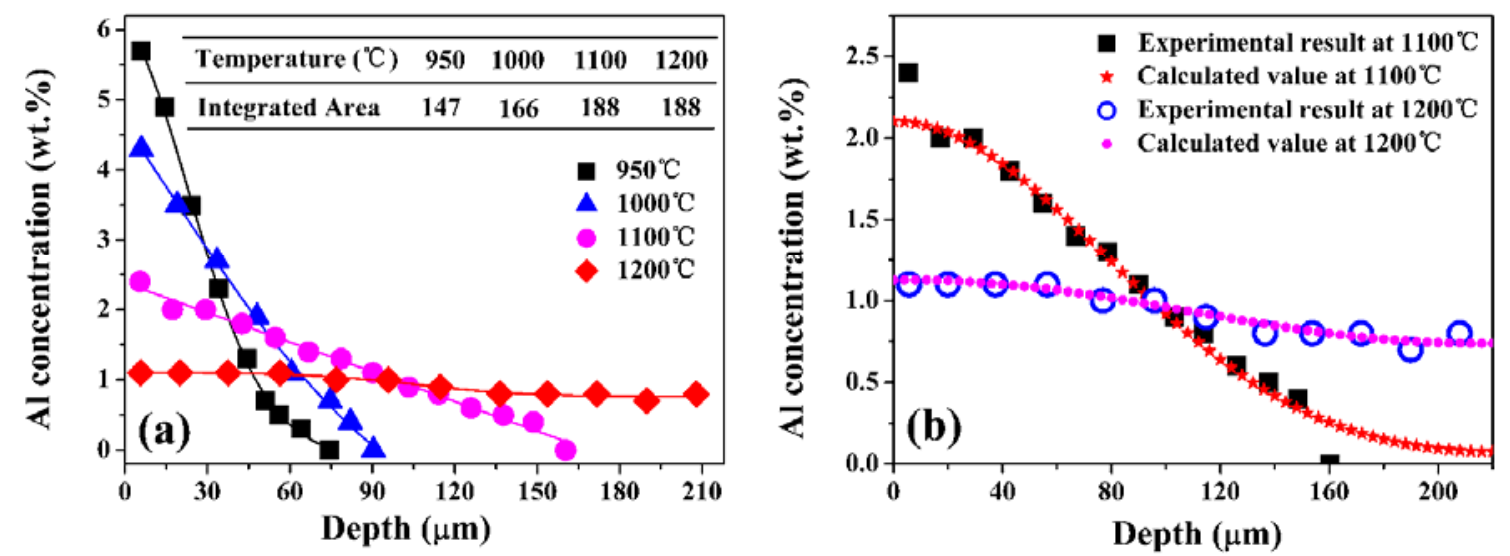

Figure 1. (a) Cross-sectional Al concentration profiles for samples deposited with $8 \mu \mathrm{m} \mathrm{Al}$ layers and annealed at different temperatures for $2 \mathrm{~h}$. The inset lists the integrated areas under the

Gauss-fitting curves representing penetrated Al amounts. (b) Comparing of calculated Al concentration with experimental results in (a).
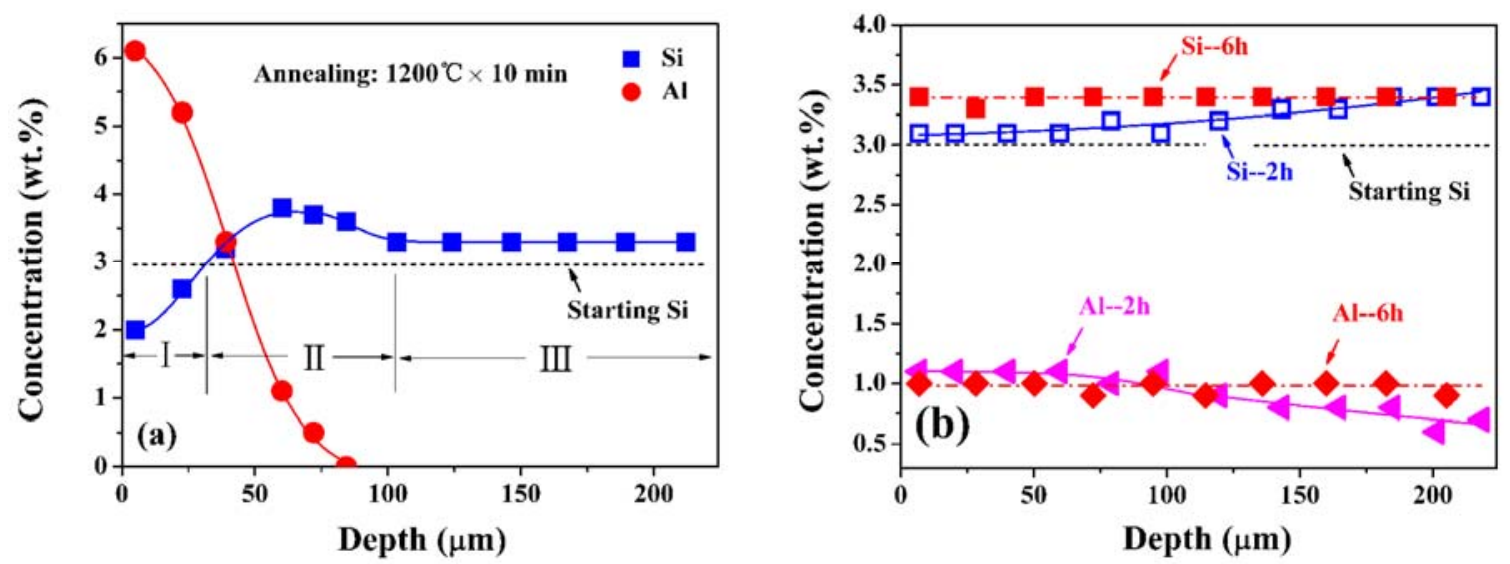

Figure 3. Both $\mathrm{Si}$ and $\mathrm{Al}$ distribution profiles along the cross-section for samples processed by coated $8 \mu \mathrm{m} \mathrm{Al}$ layer and annealed at $1200{ }^{\circ} \mathrm{C}$ for: (a) $10 \mathrm{~min}$, (b) $2 \mathrm{~h}$ and $6 \mathrm{~h}$. The dotting lines refer to Si content in the starting substrate. 


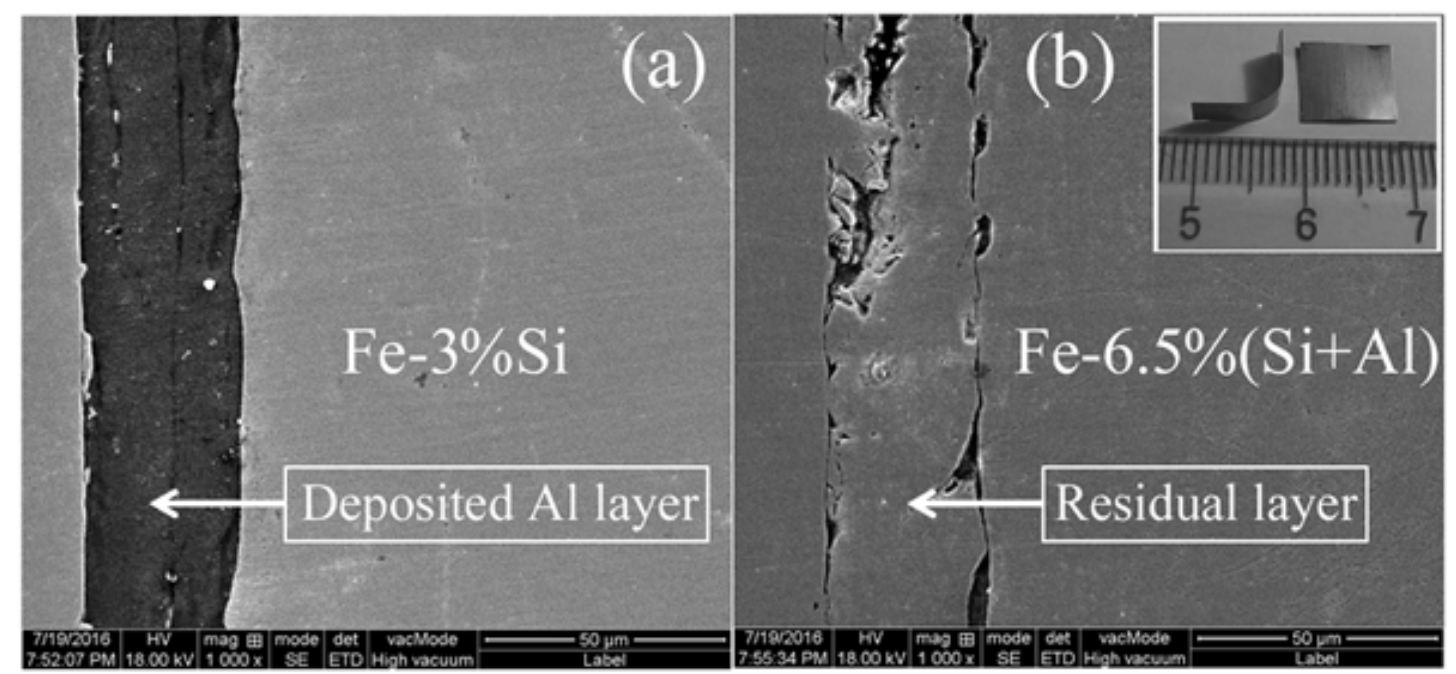

Figure 5. Cross-sectional images of as-deposited Fe-3\%Si substrate with $32 \mu \mathrm{m} \mathrm{Al} \mathrm{layer} \mathrm{(a)} \mathrm{and}$ as-annealed $\mathrm{Fe}-6.5 \%(\mathrm{Si}+\mathrm{Al})$ alloy (b). The inset shows the workability of prepared $\mathrm{Fe}-6.5 \%(\mathrm{Si}+\mathrm{Al})$ sheet being cut at ambient temperature and bend near to a right angle. 